THEORETICAI, INVESTIGATION OF TRANSMISSION LOSS FOR

DIFFERENT IN-PARALLEL TUBING CONFIGURATIONS

E.H. ROUSHDY ${ }^{+}$

ABSTRACT

A generalized formula predicting the attenuation of a main pipe branched into two in-parallel pipes joined together at their inlet and outlet in terms of the system dimensions has been 1nvest1gated. The obtalned formula reduces to that of known shapes and configurations through simple adjustments in the model. Examples of the expansion chamber and the side branch transmission loss equations have been achleved. A computer model for the system has been developed and proven applicable.

Assistant Professor, Department of Mechanical Engineering College of Engineering, Qatar University, P.0. Box 2713, Doha, Qatar. 
When a main pipe is branched into two in-parallel pipes joined together at their inlet and outlet, those pipes become acoustically coupled causing attenuation characteristics that depend mainly on the configuration dimensions. In order to account for wave motion in the axial direction of such parallel coupled system, it is necessary to relate the acoustic pressure and volume velocities at the inlet and outlet of the main pipe. Configurations of this type are of major intrest for applications in the design and analysis of mufflers and exhaust systems of internal combustion engines.

\section{THE MODEL:}

The configuration of the model is shown in Fig.(1). The continuity of acoustic pressure and volume velocity at the inlet and outlet cross sections-shown in Fig.(2) is applied using the four-pole-parameters technique ${ }^{2}$. Each transmission matrix formed by four parameters corresponds to a pipe branch, while the overall transmission matrix is formed by the four pole parameters representing the whole system. This is demonstrated in Fig.(3). The model is adopted considering that the folowing conditions hold:

(1) Elane wave propagation.

(2) Conservative system (no losses).

(a) Viscosity effects are neglected.

(b) The pipes walls neither conduct nor transmit sound energy.

(3) The propagation of sound waves is one-dimensional in the axial direction of the pipes. The cross sectional dimensions are assumed to be small compared to the wave length. Limiting frequency values are to be calculated for practical applications. Analysis must be restricted by an upper frequency bound above which the effect of the neglected higher order modes of propagation should be accounted for.

It has been successfully proven by different authors $6,7,8$ that a complex in-series system can be modeled as a four-pole net work that as long as the pipe system fulfills the assumption of 
linear plane wave theory. Using this theory the output pressure and volume velocity are dependent on the input pressure and volume velocity and constants to be obtained by experiment or theory. For branches (a) and (b) of Fig.(3), the acoustic pressure and volume velocities are related as follows:

$$
\begin{aligned}
& P_{1 a}=A_{1} P_{2 a}+A_{2} U_{2 a} \\
& U_{1 a}=A_{3} P_{2 a}+A_{4} U_{2 a} \\
& P_{1 b}=B_{1} P_{2 b}+B_{2} U_{2 b} \\
& U_{1 b}=B_{3} P_{2 b}+B_{4} U_{2 b}
\end{aligned}
$$

It has been shown by reciprocity theorem that:

$$
\begin{aligned}
& A_{1} A_{4}-A_{2} A_{3}=1 \\
& B_{1} B_{4}-B_{2} B_{3}=1
\end{aligned}
$$

For the main pipe, this relation could be written as:

$$
\begin{aligned}
& \mathrm{P}_{1}=\mathrm{C}_{1} \mathrm{P}_{2}+\mathrm{C}_{2} \mathrm{U}_{2} \\
& \mathrm{U}_{1}=\mathrm{C}_{3} \mathrm{P}_{2}+\mathrm{C}_{4} \mathrm{U}_{2}
\end{aligned}
$$

where $\left(C_{1}, C_{2}, C_{3}, C_{4}\right)$ are the four-pole-parameters of the overal transwission matrix of the main pipe. They are to be expressed in terms of $\left(A_{1}, A_{2}, A_{3}, A_{4}\right)$ and $\left(B_{1}, B_{2}, B_{3}, B_{4}\right)$ subject to

the following boundary condition:

$$
\begin{aligned}
P_{1} & =P_{1 a}=P_{1 b} \\
P_{2} & =P_{2 a}=P_{2 b} \\
U_{1}=U_{1 a} & =U_{1 b}
\end{aligned}
$$




\section{\begin{tabular}{l|l} 
ANC -5 & 48
\end{tabular}}

$\mathrm{U}_{2}=\mathrm{U}_{2 \mathrm{a}}+\mathrm{U}_{2 \mathrm{~b}}$

The four pole parameters $\left(C_{1}, C_{2}, C_{3}, C_{4}\right)$ appearing in equations

(5) and (6) expressed in terms of $\left(A_{1}, A_{2}, A_{3}, A_{4}\right)$ and $\left(B_{1}, B_{2}, B_{3}\right.$, $\left.\mathrm{B}_{4}\right)$ are $^{*}$

$$
\begin{aligned}
& C_{1}=\frac{A_{1} B_{2}+A_{2} B_{1}}{A_{2}+B_{2}} \\
& C_{2}=\frac{A_{2} B_{2}}{A_{2}+B_{2}} \\
& C_{3}=\frac{A_{2} B_{3}+A_{3} B_{2}+A_{1} B_{4}+A_{4} B_{1}-2}{A_{2}+B_{2}} \\
& C_{4}=\frac{A_{2} B_{4}+A_{4} B_{2}}{A_{2}+B_{2}}
\end{aligned}
$$


It is understood that the transmission loss could also be found by taking the ratio of pressure levels at both ends of the main pipe:

$$
\mathrm{TL}=20 \log _{10}\left[\frac{\mathrm{P}_{2}}{\mathrm{P}_{1}}\right]
$$

In terms of the four-pole-parameters $\left(C_{1}, C_{2}, C_{3}, C_{4}\right)$ this transaction loss is given by ${ }^{2}$ :

$$
\mathrm{TL}=20 \log _{10} \frac{1}{2}\left|\left(C_{1}+\frac{S}{\rho C} \quad C_{2}+\frac{\rho c}{s} \quad C_{3}+C_{4}\right)\right|
$$

using the drived values of the parameters; the transmission loss equation becomes:

$\mathrm{TL}=20 \log _{10}\left[\frac{\left(A_{1} B_{2}+A_{2} B_{1}\right)+\frac{S}{P C}\left(A_{2} B_{2}\right)+\frac{P C}{S}\left(A_{2} B_{3}+A_{3} B_{2}+A_{1} B_{4}+A_{4} B_{1}-2\right)+\left(A_{2} B_{4}+A_{4} B_{2}\right)}{2\left(A_{2}+B_{2}\right)}\right]$

For the case under study where the two branches are simple plpes of cross sectional areas $\left(s_{a}\right),\left(s_{b}\right)$, and lengths $\left(l_{a}\right),\left(l_{b}\right)$

the four-pole parameters of the branches are:

$$
\begin{array}{ll}
\mathrm{A}_{1}=\cos \mathrm{k}_{\mathrm{a}} & \mathrm{B}_{1}=\cos \mathrm{k}_{\mathrm{b}} \\
\mathrm{A}_{2}=1 \frac{\rho \mathrm{c}}{\mathrm{S}_{\mathrm{a}}} \sin \mathrm{k}_{\ell_{\mathrm{a}}} & \mathrm{B}_{2}=1 \frac{\rho \mathrm{c}}{\mathrm{S}_{\mathrm{b}}} \sin \mathrm{k}_{\ell_{\mathrm{b}}} \\
\mathrm{A}_{3}=1 \frac{\mathrm{s}}{\rho \mathrm{c}} \sin \mathrm{k}_{\mathrm{a}} & \mathrm{B}_{3}=1 \frac{\mathrm{S}_{\mathrm{b}}}{\rho \mathrm{c}} \sin \mathrm{k}_{\mathrm{b}} \\
\mathrm{A}_{4}=\cos \mathrm{k}_{\mathrm{a}} & \mathrm{B}_{4}=\operatorname{Cos} \mathrm{k}_{\mathrm{b}}
\end{array}
$$

The corresponding four-pole-parameters forming the overall transmisson matrix are:

$$
C_{1}=\frac{s_{a} \cos k_{a} \sin k_{b}+s_{b} \sin k_{a} \cos k l_{b}}{S_{b} \sin k_{a}+S_{a} \sin k_{b}}
$$




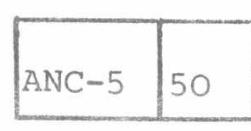

FIRST A.M.E. CONFERENCE

$$
\begin{aligned}
& c_{2}=(j \rho c) \frac{\operatorname{sink} \ell_{a} \sin k_{b}}{S_{b} \sin k \ell_{a}+S_{a} \operatorname{Sin} k_{b}} \\
& C_{3}=\left(\frac{1}{\rho c}\right) \frac{\left(S_{a}^{2}+s_{b}^{2}\right) \sin k \ell_{a} \sin k_{b}+2 s_{a} S_{b}-2 s_{a} s_{b} \cos k_{a} \cos k_{b}}{s_{b} \sin k_{a}+S_{a} \sin k_{b}} \\
& c_{4}=\frac{s_{a} \cos k \ell_{a} \sin k \ell_{b}+s_{b} \sin k_{a} \cos k \ell_{b}}{s_{b} \operatorname{sink} \ell_{a}+s_{a} \sin k \ell_{b}}
\end{aligned}
$$

And the general formula of transmission loss for such ocnfiguration becomes:

$$
\begin{aligned}
& \mathrm{T} \cdot \mathrm{L}=10 \log _{10}\left\{\left[\left(\mathrm{~S}_{\mathrm{a}} \operatorname{Cos} \mathrm{k}_{\mathrm{a}} \operatorname{Sin} \mathrm{k}_{\mathrm{b}}+\mathrm{S}_{\mathrm{b}} \operatorname{Sin} \mathrm{k}_{\mathrm{a}} \operatorname{Cos} \mathrm{k}_{\mathrm{b}}\right)^{2}\right.\right. \\
& +\left(\frac{s_{a}^{2}+s_{b}^{2}+s^{2}}{2 s} \quad \text { sin k } \ell_{a} \sin k \ell_{b}+\left(\frac{s_{a} S_{b}}{s}\right)\right. \\
& \left.\left.\left.\left(1-\operatorname{Cos} k_{a} \ell_{a} \cos \ell_{b}\right)\right)^{2}\right] /\left(s_{a} \sin k_{a}+s_{b} \sin k_{a}\right)\right\} \ldots \ldots
\end{aligned}
$$

\section{INVESTIGATION OF TRANSMISSION LOSS FOR PIPE CONFIGURATIONS OF KNOWN}

\section{RESULTS:}

The transmission loss formula (21) is assumed applocable to any inversion of the in-parallel-branched plpe configuration. A computer program to verify the model has been developed. To verify the model, two test cases (the expansion chamber and the tuned side branch) have been considered:

\section{(a) Expansion Chamber:}

Considering the assumption stated for the model shown in Fig. (1), this model will converge to an expansion chamber by $\operatorname{setting} l_{\mathrm{a}}=l_{\mathrm{b}}=\ell$ as shown in Fig.(4) Transmission loss curve for an expansion chamber and the frequencies of maximum and minimum attenuation are shown in F $1 g \cdot(5)$.

Let $\frac{S_{a}+S_{b}}{S}=m$, and substituting these values in 
equation (21):

$$
\text { N.T.L. }=10 \log _{10}\left[1+\frac{1}{4}(\mathrm{~m}-1 / \mathrm{m})^{2} \operatorname{Sin}^{2} \mathrm{k} \ell\right]
$$

The general formula of transmission loss for the model under study (21) reduces to that of an expansion chamber. Figures (6) and (7) show the transmission loss predicted by the developed model for two selected values of (m).

(b) Tuned side branch:

If one of the side braches' length is set to (zero) with the length of the other branch set to ( $l)$, the model reduces to that of a side branch with a length $(l / 2)$ and a cross sectional area of $\left(2 S_{a}\right)$ as in Fig.(8). A typical transmission loss curve for a turned side branch and the frequencles of maximum and minimum attenuation is shown in Fig. (9).

$$
\begin{aligned}
& \text { Set }=\frac{2 \mathrm{~S}_{\mathrm{a}}}{\mathrm{S}} \text {, and substituting those values in } \\
& \text { equation }(21): \\
& \ldots \mathrm{T} \cdot \mathrm{L}=10 \log _{10}\left[1+\frac{1}{4}\left(\frac{\mathrm{m}}{\operatorname{Cot} \mathrm{k} l / 2}\right)^{2}\right] \ldots
\end{aligned}
$$

The general formula of transmission loss for the model under study (21) reduces to that of a tuned side branch. Figures (10), and (11) show the transmission loss predicted by the developed model for selected values of (m).

\section{CONCLUSIONS AND RECOMMENDATIONS:}

The use of the four-pole-parameters technique to relate acoustic pressure and volume velocities between the inlet and outlet of a main pipe branched Into two in-parallel pipes has proven to be useful to calculate the attenuation in the configuration. The driven generalized formula is flexible and applicable to many inversions of the model under study. This formula should be of major interest to 
those involved in the design and analysis of mufflers and exhaust systems of internal combustion engines where numerous shapes and configurations ofthis sort are used.

It is recommended that the developed formula not only be applied to in-parallel branched pipes, but also be used to investigate and predict acoustic characteristics of more complicated shapes through rearranging the configuration under study to fit the model.

\section{Nomenclature:}

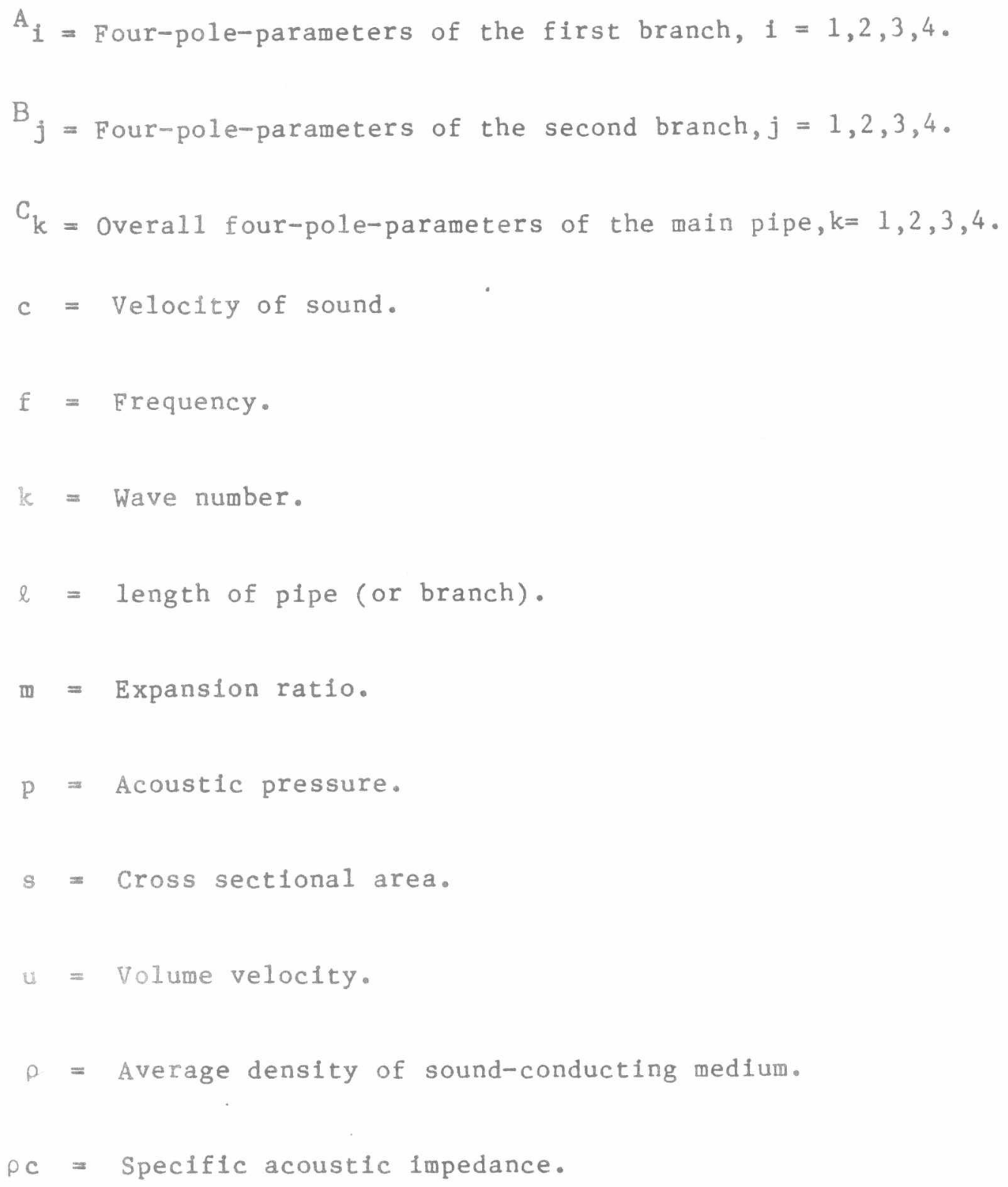




\section{References:}

(1) Roushdy, E.H. "one dimensional model for the muffler reversing section", Herrick laboratories internal report 78-9-21 Purdue University, 1978.

(2) Sulivan, J.W. "Application of transmission matrices to parallel coupled acoustic duct configurations", Herrick Laboratories internal report 76-7. Purdue University, 1976.

(3) Sullivan, J.W. "Theory and methods for modeling acoustcally long unpartitioned cavity resonators for engine exhaust systems", Ph.D. thesis, Purdue University, Dec. 1974.

(4) Patrick, W.P. "Systematic method to determine the acoustical characteristics of series-parallel duct configurations using transmission matrices", presented at Acoustical Society of America meeting, San Francisco, Nov. 4-7, 1975.

(5) Davis Jr. D., Stokes G., Moore D., and Stevens Jr. G., "Theoretical and experimental investigation of mufflers with comments on engine exhaust muffler design", Langley Aero- nautical Laboratory, Report 1192 .

(6) Young J., Crocker M.J., "Acoustic analysis of mufflers for engine exhaust systems", Herrick Laboratories, Report No. 11 August 1973.

(7) Rschekin, S.N. "The theory of sound", Pergamon Press, Handan, 1963.

(8) Morse P.M., Ingard K.U., "Theoretical Acoustics", McGraw Hill, New York, 1978 .

(9) Kinsler L.E., Frey A.R., "Fundamentals of Acoustics", John Wiley and Sons, New York, 1962. 


\section{Appendix}

(a) Development of the general mode1:

Equations (1) and (3) give:

$$
\begin{aligned}
& \left(P_{1 a}+P_{1 b}\right)=\left(A_{1} P_{2 a}+B_{1} P_{2 b}\right)+\left(A_{2} U_{2 a}+B_{2} U_{2 b}\right) \cdots(A-1) \\
& 2 \mathrm{P}_{1}=\left(\mathrm{A}_{1}+\mathrm{B}_{1}\right) \mathrm{P}_{2}+\mathrm{A}_{2}\left(\mathrm{U}_{2}-\mathrm{U}_{2 \mathrm{~b}}+\mathrm{B}_{2} \mathrm{U}_{2 \mathrm{~b}}\right. \\
& 2 \mathrm{P}_{1}=\left(\mathrm{A}_{1}+\mathrm{B}_{1}\right) \mathrm{P}_{2}+\mathrm{A}_{2} \mathrm{U}_{2}+\left(\mathrm{B}_{2}-\mathrm{A}_{2}\right) \mathrm{U}_{2 \mathrm{~b}} \quad \ldots .(\mathrm{A}-2)
\end{aligned}
$$

Equations (2) and (4) give:

$$
\begin{aligned}
& \left(\mathrm{U}_{1 \mathrm{a}}+\mathrm{U}_{1 \mathrm{~b}}\right)=\left(\mathrm{A}_{3} \mathrm{P}_{2 \mathrm{a}}+\mathrm{B}_{3} \mathrm{P}_{2 b}\right)+\left(\mathrm{A}_{4} \mathrm{U}_{2 \mathrm{a}}+\mathrm{B}_{4} \mathrm{U}_{2 b}\right) \\
& \mathrm{U}_{1}=\left(\mathrm{A}_{3}+\mathrm{B}_{3}\right)+\mathrm{A}_{4}\left(\mathrm{U}_{2}-\mathrm{U}_{2}\right)+\mathrm{B}_{4} \mathrm{U}_{2} \mathrm{~b} \\
& \mathrm{U}_{1}=\left(\mathrm{A}_{3}+\mathrm{B}_{3}\right)+\mathrm{A}_{4} \mathrm{U}_{2}+\left(\mathrm{B}_{4}-\mathrm{A}_{4}\right) \mathrm{U}_{2} \mathrm{~b} \ldots(\mathrm{A}-3)
\end{aligned}
$$

Subtracting equation (3) from (1) gives:

$$
\begin{aligned}
\left(P_{1 a}-P_{1 b}\right) & =\left(A_{1}-B_{1}\right) P_{2}+\left(A_{2} U_{2 a}-B_{2} U_{2 b}\right) \\
0 & =\left(A_{1}-B_{1}\right) P_{2}+A_{2}\left(U_{2}-U_{2 b}\right)-B_{2} U_{2 b} \\
0 & =\left(A_{1}-B_{1}\right) P_{2}+A_{2} U_{2}-\left(A_{2}+B_{2}\right) U_{2 b} \\
U_{2 b}= & {\left[\frac{A_{1}-B_{1}}{A_{2}+B_{2}}\right] P_{2}+\left[\frac{A_{2}}{A_{2}+B_{2}}\right] U_{2} \ldots . . . . }
\end{aligned}
$$

Substituting for $\mathrm{U}_{2 \mathrm{~b}}$ as expressed by equation (A-4):

1. In equation (A-2)

$P_{1}=\left[\frac{A_{1}+B_{1}}{2}\right] P_{2}+\left[\frac{A_{2}}{2}\right] U_{2}-\left[\frac{\left(A_{2}-B_{2}\right)\left(A_{1}-B_{1}\right)}{2\left(A_{2}+B_{2}\right)}\right] P_{2}+\left[\frac{A_{2}\left(B_{2}-A_{2}\right)}{2\left(A_{2}+B_{2}\right)}\right] U_{2}$ 
$P_{1}=\left[\frac{A_{1} B_{2}+A_{2} B_{1}}{A_{2}+B_{2}}\right] P_{2}+\left[\frac{A_{2} B_{2}}{A_{2}+B_{2}}\right] U_{2}$

11. In equation (8)

$$
\begin{aligned}
& U_{1}=\left(A_{3}+B_{3}\right) P_{2}+A_{4} U_{2}-\left[\frac{\left(A_{1}-B_{1}\right)\left(A_{4}-B_{4}\right)}{\left(A_{2}+B_{2}\right)}\right] P_{2}-\left[\frac{A_{2}\left(A_{4}-B_{4}\right)}{\left(A_{2}+B_{2}\right)}\right] U_{2} \\
& U_{1}=\left[\frac{A_{2} B_{3}+A_{3} B_{2}+A_{1} B_{4}+A_{4} B_{1}-2}{A_{2}+B_{2}}\right] P_{2}+\left[\frac{A_{2} B_{4}+A_{4} B_{2}}{A_{2}+B_{2}}\right] U_{4} \ldots .(A-6)
\end{aligned}
$$

The four pole parameters $\left(C_{1}, C_{2}, C_{3}, C_{4}\right)$ appearing in equations (5) and (6) and expressed in terms of ( $A, A, A, A)$ and $\left({ }_{1} B, 2^{B}, 3^{B}, 4^{B}\right.$, ) are:

$$
\begin{aligned}
& C_{1}=\frac{A_{1} B_{2}+A_{2} B_{1}}{A_{2}+B_{2}} \\
& C_{2}=\frac{A_{2} B_{2}}{A_{2}+B_{2}} \\
& C_{3}=\frac{A_{2} B_{3}+A_{3} B_{2}+A_{1} B_{4}+A_{4} B_{1}-2}{A_{2}+B_{2}} \\
& C_{4}=\frac{A_{2} B_{4}+A_{4} B_{2}}{A_{2}+B_{2}}
\end{aligned}
$$

The paraweters satisfy the condition

$$
\mathrm{C}_{1} \mathrm{C}_{4}-\mathrm{C}_{2} \mathrm{C}_{3}=1
$$

(b) Transmission loss expression for an expansion chamber:

$$
\begin{aligned}
& \therefore T \cdot L \cdot=10 \log _{10}\left[\cos ^{2} k l+\left(\frac{\sin ^{2} k \ell}{2 S}\left((S+S)^{2}+S^{2}\right)\right)^{2} /(S+S)^{2} \sin ^{2} k l\right] \\
& =10 \log _{10}\left[1-\sin ^{2} k l+\sin ^{2} k \ell\left(\frac{1}{4}\left(\frac{s_{a}+s_{b}}{s}\right)^{2}\right.\right.
\end{aligned}
$$


ANC -5

$$
\begin{aligned}
& \left.\left.+\frac{1}{4}\left(\frac{s}{s_{a}+s_{b}}\right)^{2}+\frac{1}{2}\right)\right] \\
& =10 \log _{10}\left[1+\frac{1}{4}\left(m^{2}-1+1 / m^{2}\right) \sin ^{2} k \ell\right] \\
& =10 \log _{10}\left[1+\frac{1}{4}(m-1 / m)^{2} \sin ^{2} k l\right]
\end{aligned}
$$

(c) Transmission loss expression for a tuned side branch

$$
\begin{aligned}
\mathrm{T} . \mathrm{L} . & =10 \log _{10}\left[1+\left(\frac{\mathrm{s}_{\mathrm{a}}}{\mathrm{s}}\right)^{2}\left(\frac{1-\cos \mathrm{k} \ell}{\mathrm{sin} \mathrm{k} \ell}\right)^{2}\right] \\
& =10 \log _{10}\left[1+\frac{1}{4} \mathrm{~m}\left(\frac{\left(1-\cos ^{2} \mathrm{k} \ell / 2\right)+\sin ^{2} \mathrm{k}_{\ell} / 2}{2 \sin \mathrm{k} \ell / 2 \cos \mathrm{k} \ell / 2}\right)^{2}\right] \\
\mathrm{T} \cdot \mathrm{L} & =10 \log _{10}\left[1+\frac{1}{4}\left(\frac{\mathrm{m}}{\cot \mathrm{k} \ell / 2}\right)^{2}\right]
\end{aligned}
$$

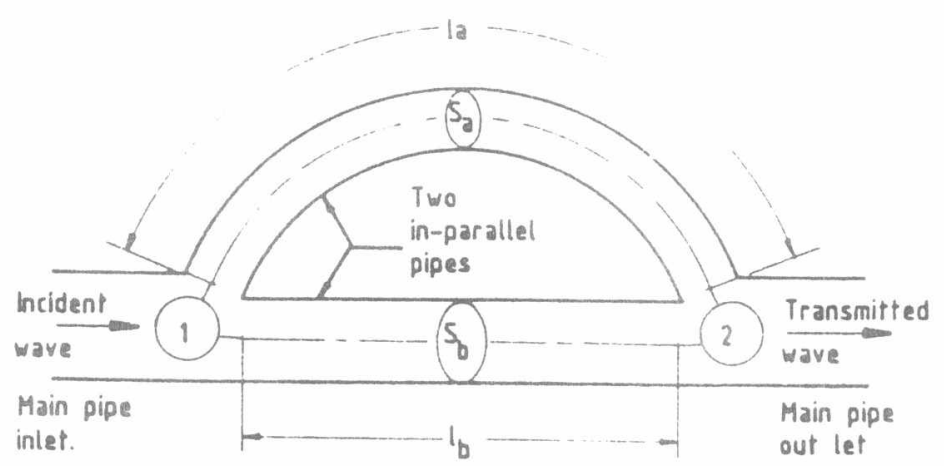

FIG. (1) Configuration of the model under study
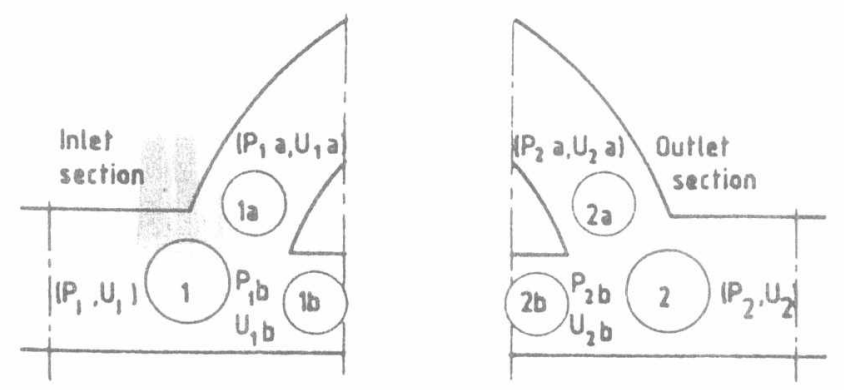

FIG.(2) Acoustic pressure and volume velocity at 


$$
\begin{array}{|l|l|}
\hline \text { ANC }-5 & 57 \\
\hline
\end{array}
$$

\section{FIRST A.M.E. CONFERENCE 29-31 May 1984, Cairo}
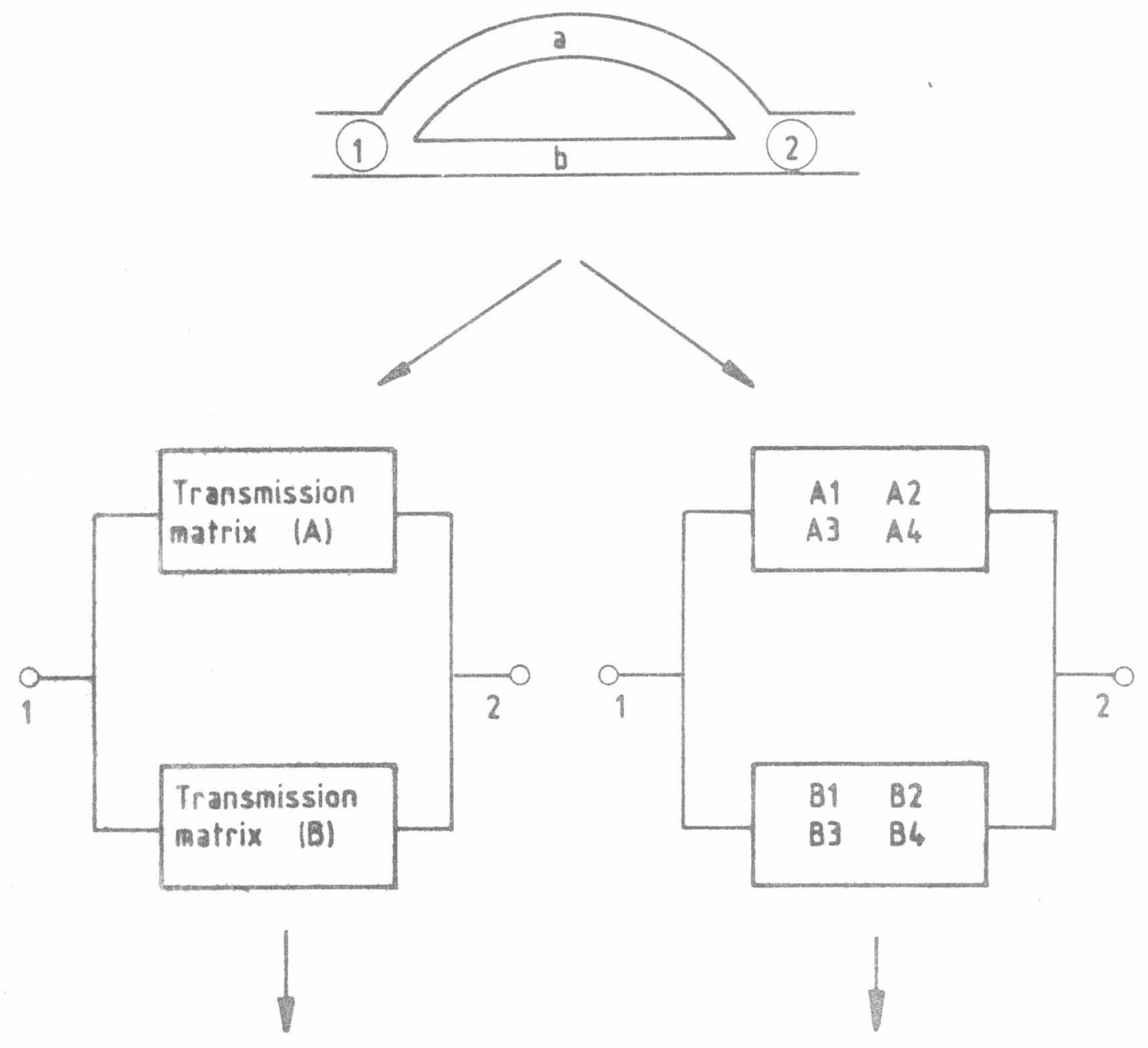

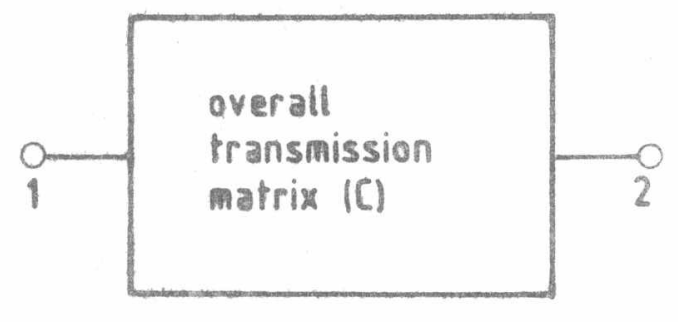

(a) Transmission matrix between stations

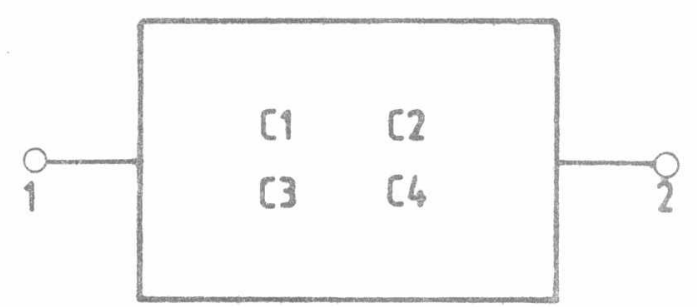

(b) Four - pole parameters

FIG. (3) Modeling of the system 


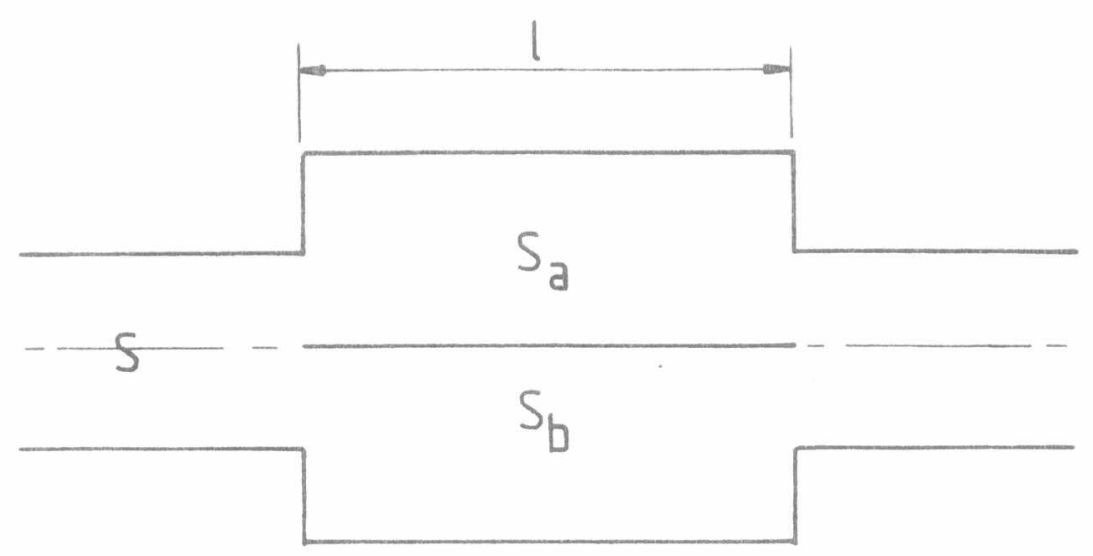

FIG. (4) Two-in-parallel pipes of equal lengths (Expansion chamber).

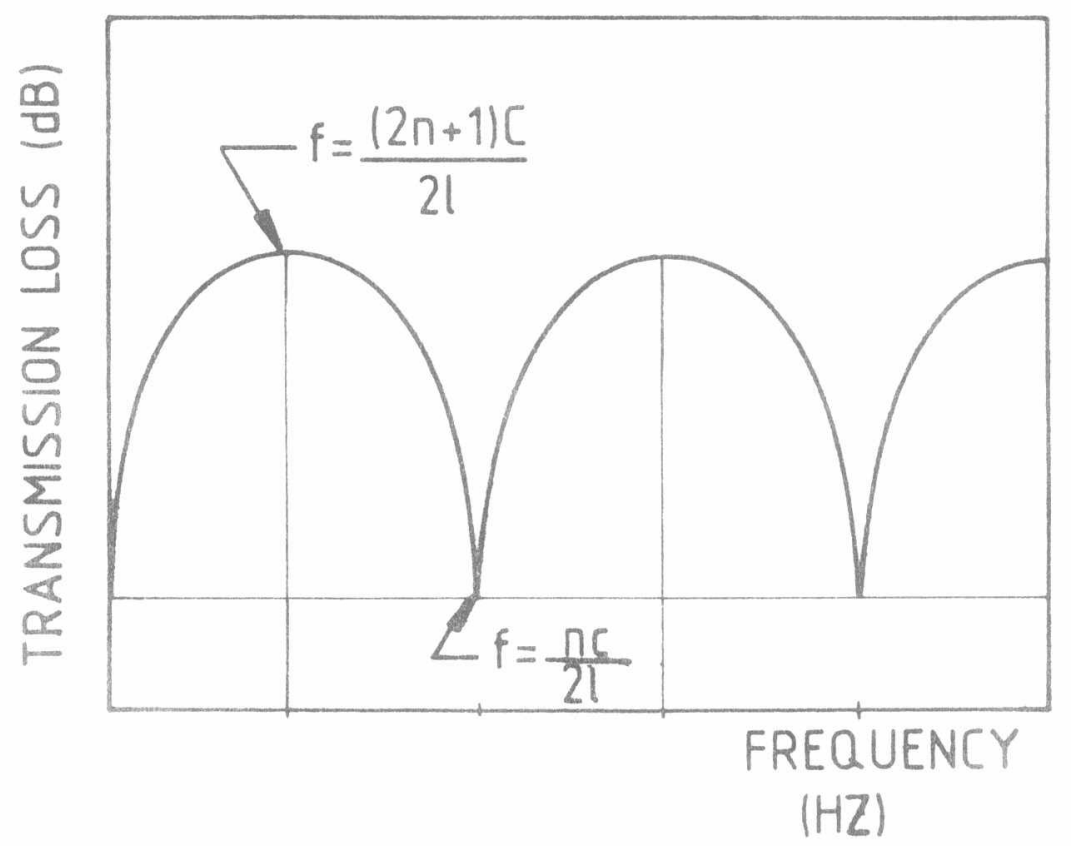

FIG. (5) Shape of transmission loss characteristics of the expansion chamber. 
!

$\vdots$

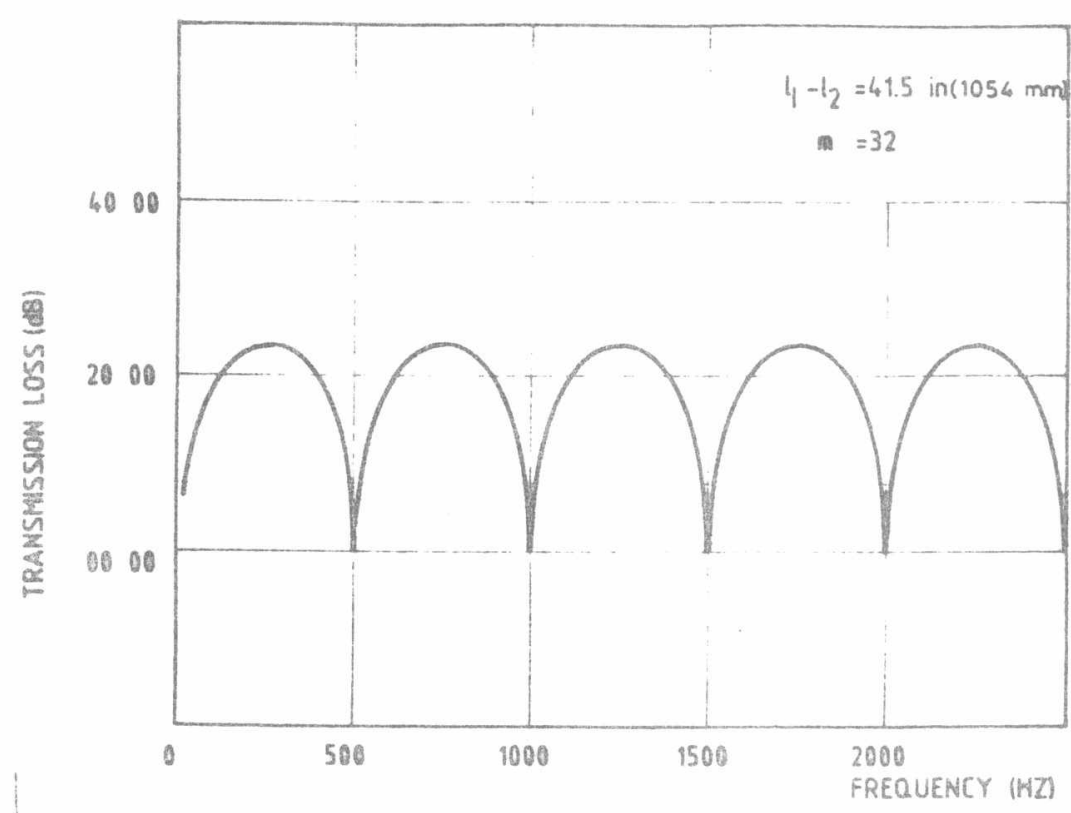

Fic. (6) Predicted transmission loss charateristics of an expansion chamber using the developed model.

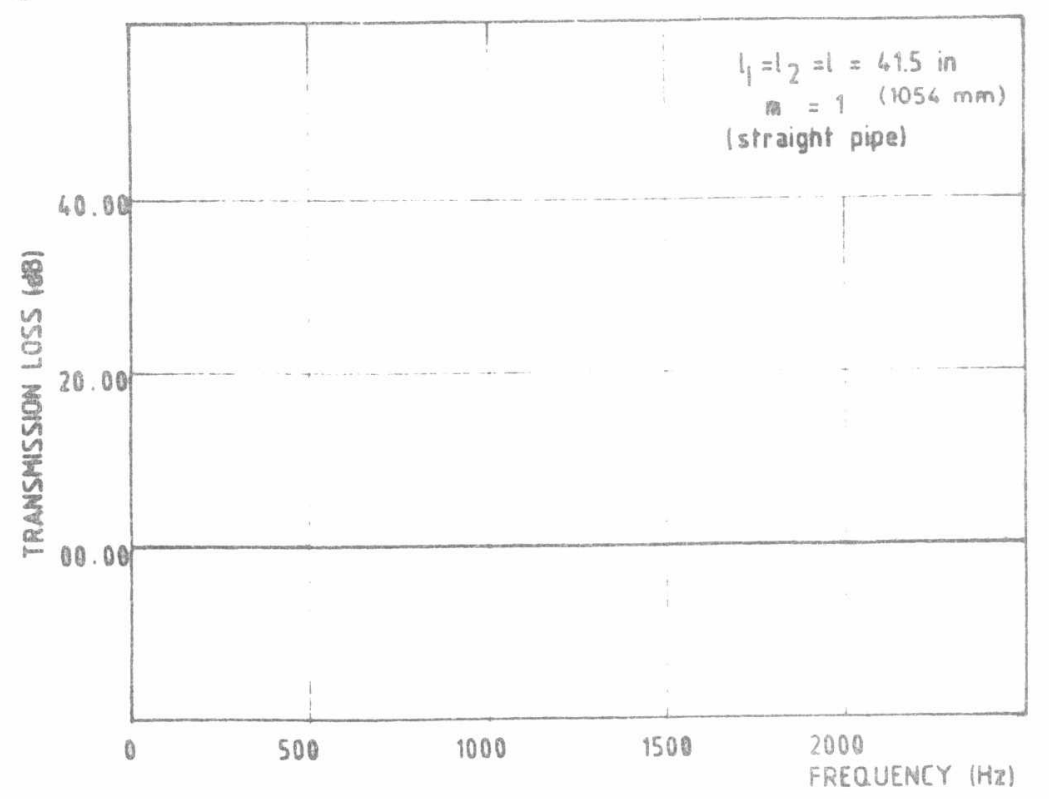

FIG. (7) Predicted transmission loss characteristics of a straight pipe (a special case of the expansion chamber) using the developed rnodel. 


\begin{tabular}{|l|l|}
\hline ANC-5 & 60 \\
\hline
\end{tabular}

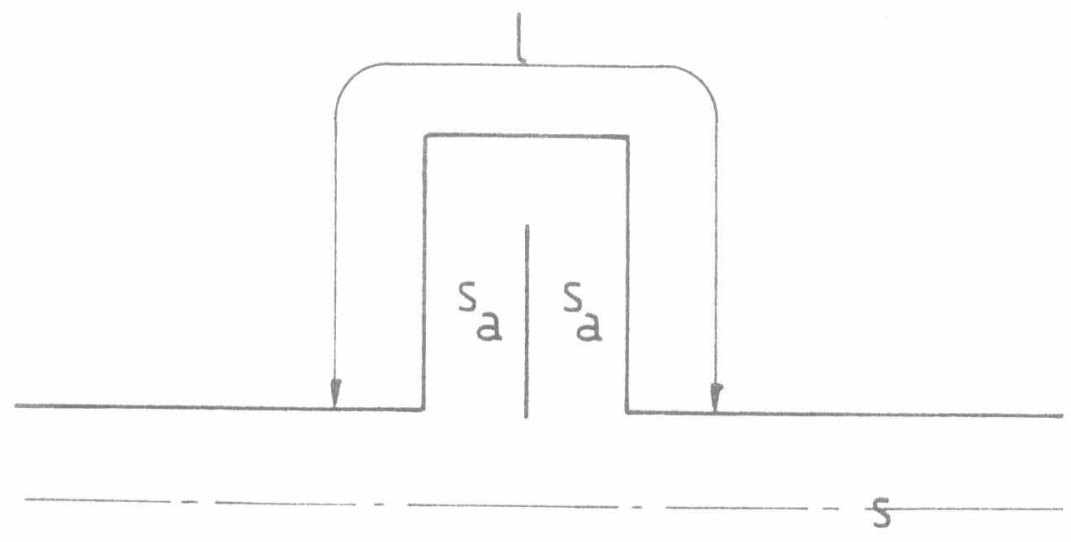

FIG. (8) Two-in-parallel pipes with one length set to zero (tuned side branch)

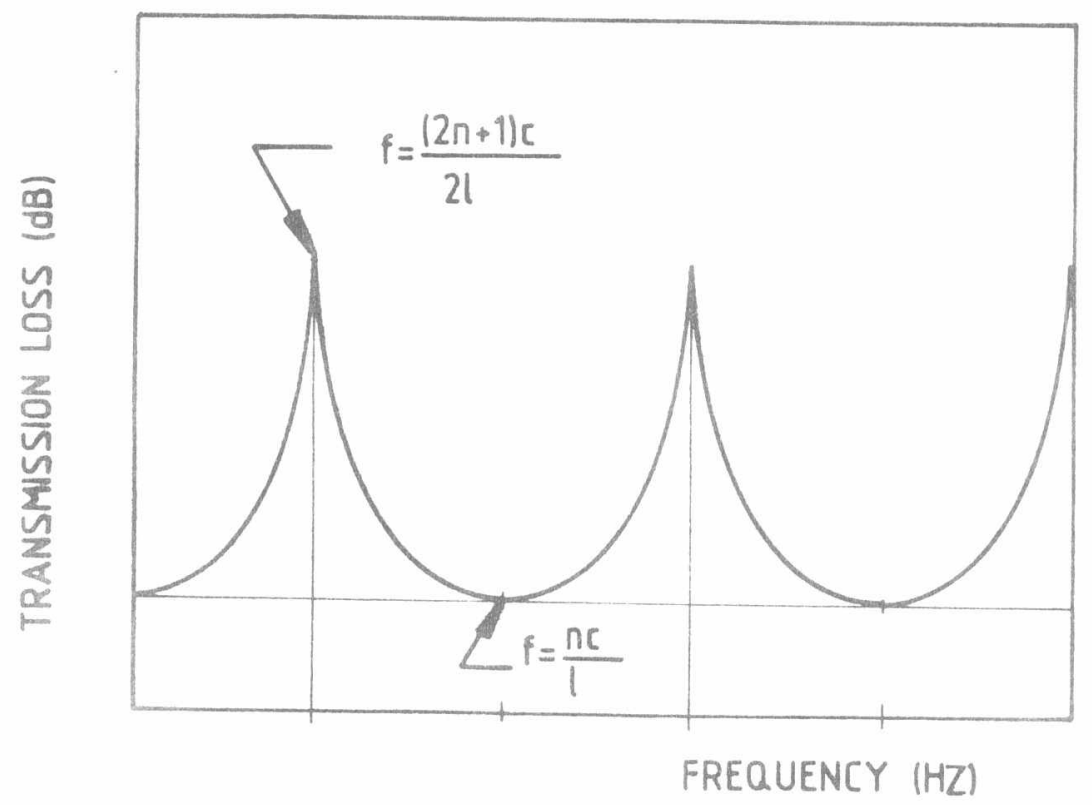

FIG. (9) Shape of transmission loss characteristics of the tuned side branch. 


\begin{tabular}{l|l|}
\hline ANC-5 & 61 \\
\hline
\end{tabular}

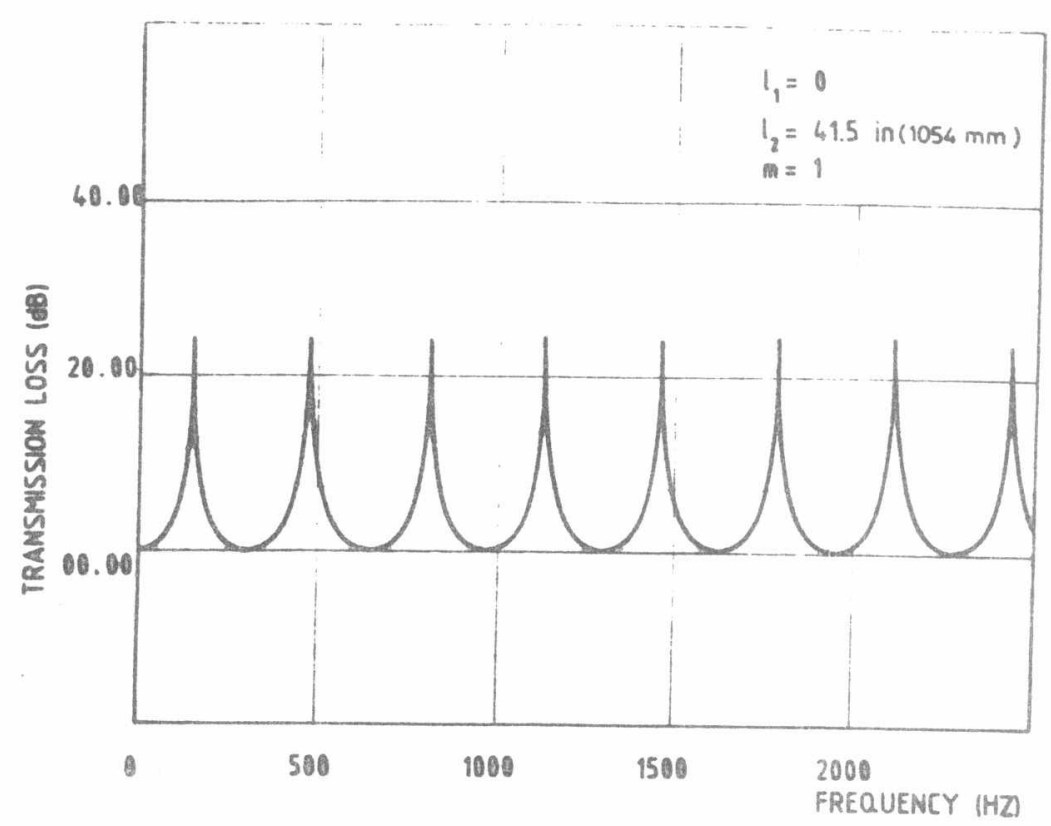

FIG. (9) Predicted transmission losg characteristics of a funed side branch using the developed model.

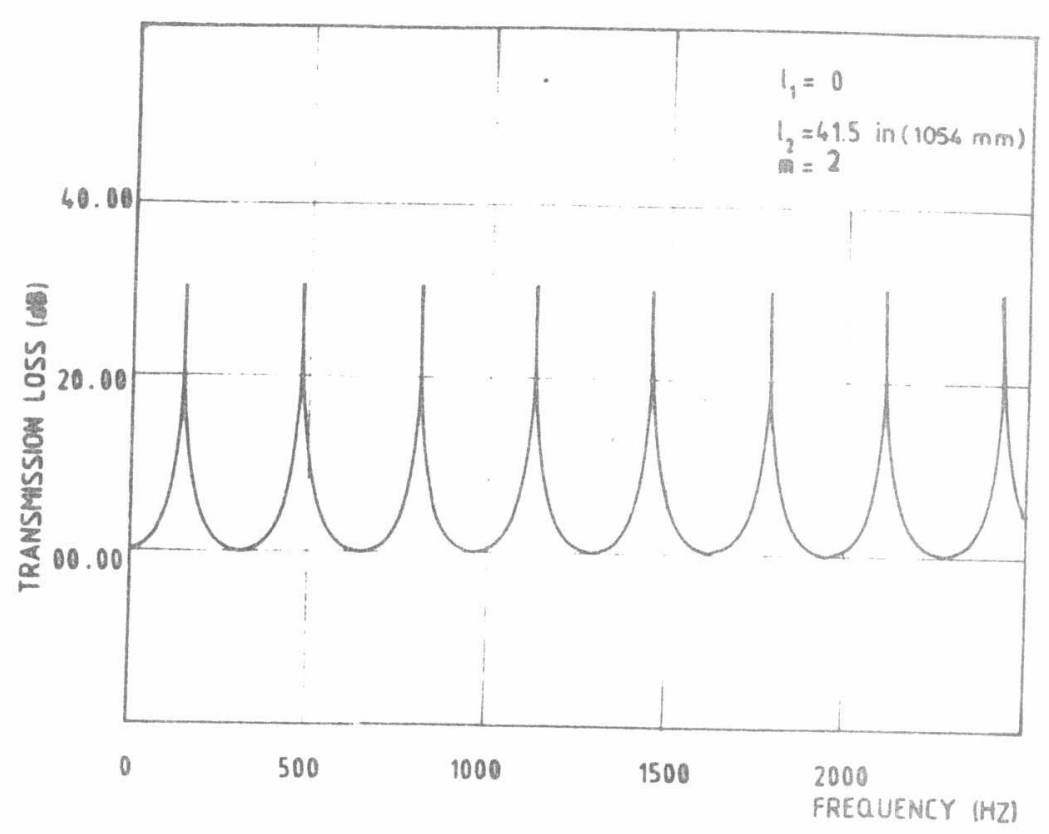

FIG. (10) Predicted transmission loss characteristics of a funed side branch using the developed model. 
